\title{
СТАТИЧЕСКИЙ ПАРОФАЗНЫЙ ГАЗОХРОМАТОГРАФИЧЕСКИЙ АНАЛИЗ С МАСС-СПЕКТРОМЕТРИЧЕСКИМ ДЕТЕКТИРОВАНИЕМ В ЛАБОРАТОРНОМ МОДЕЛИРОВАНИИ ПОВЕДЕНИЯ СИСТЕМЫ «НЕФТЬ - ВОДА»
}

\author{
Ю.С. ТОКСАРОВА \\ Горный институт УрО РАН, г. Пермь
}

\begin{abstract}
Аннотация: Предложены параметры хроматографирования и парофазного анализа водорастворимых компонентов нефти. На основе данных, полученных в ходе парофазного хроматографического анализа, установлен состав летучих органических соединений водной фракции системы «нефть-вода». По реперным ароматическим углеводородам определены индексы Ковача, характеризующие подвижность на 5\%фенил-95\%-диметилполисилоксановой колонке нефтяных аквабитумоидов.

Ключевые слова: газовая хроматография/Масс-спектрометрия, статический парофазный анализ, ароматические углеводороды, структурные изомеры, вода, дозатор равновесного пара, 5\%-Фенил-95\%диметилполисилоксан.
\end{abstract}

Пристальное внимание к изучению органических веществ в природных водах связано с проблемами охраны и контроля окружающей среды от загрязнений. Для получения качественной и количественной информации о водорастворенном органическом веществе в последнее время широко используются хроматографические методы анализа в сочетании с различными способами пробоподготовки [1-5]. В XXI веке все большее внимания уделяется внедрению методов определения углеводородов на основе техники газовой хроматографии/масс-спектрометрии (ГХ/МС) [3]. Идентификация аналитов по библиотечным масс-спектрам, а при необходимости по индексам удерживания практически полностью исключает ошибки [6].

С целью получения опорных аналитических характеристик нефтяных аквабитумоидов как диагностической основы поисковых и экологических маркеров в условиях различного аппаратурного оформления хроматографического анализа проводилось экспериментальное моделирование поведения системы «нефть - вода». В качестве объектов исследования использованы нефти, отобранные из эксплуатационных скважин нефтяных месторождений Пермского Прикамья и дистиллированная вода.

Анализ органических соединений, извлеченных водой при суточном контакте с нефтью, проводился по трем методикам:Пробоподготовка методом жидкой экстракции в хлороформ $[7,8]$, растворение экстракта в гексане. Условия анализа: хромато-масс-спектрометрическая система 6890N/5973N фирмы «Agilent Technologies», хроматографическая колонка HP-5MS (5\%-фенил-95\%-диметилполисилоксан) длиной 30 м, внутренним диаметром 0,25 мм, с толщиной неподвижной фазы 0,25 мкм. Скорость газа-носителя (гелий) 1 мл/мин, давление 57,3 кПа. Программируемый нагрев от $80{ }^{\circ} \mathrm{C}$ до $250^{\circ} \mathrm{C}$, со скоростью 70 град/мин, далее изотермический на верхней границе интервала. Температура интерфейса $250{ }^{\circ} \mathrm{C}$, температура квадруполя $150{ }^{\circ} \mathrm{C}$, температура источника ионов $230^{\circ} \mathrm{C}$. Задержка на растворитель 5 минут, деление потока 1:10. Масс-спектр записывался по полному ионному току.

1. Автоматическая статическая газовая экстракция соединений из образца: 10 мл воды в герметично закрытых флаконы вместимостью 20 мл помещают в карусель парофазного дозатора TurboMatrix HS. Флаконы термостатировали в течение 15 минут при температуpe $80{ }^{\circ} \mathrm{C}$. Температура иглы $-90^{\circ} \mathrm{C}$, температура линии переноса $-95^{\circ} \mathrm{C}$, время введения пробы 0,15 минуты, давление ввода 200 кПа, давление в колонке 150 кПа. Условия хроматографирования см. выше. Программируемый нагрев начинали с $95^{\circ} \mathrm{C}$.

2. Условия автоматической газовой экстракции см. выше. Условия анализа: колонка DB-5MS (5\%-фенил-95\%-диметилполисилоксан) длиной 60 м, внутренним диаметром 0,25 мм, с толщиной неподвижной фазы 1 мкм, давление в системе увеличено до 170 кПа, начальная температура инжектора повешена до $95{ }^{\circ} \mathrm{C}$. Без задержки на растворитель. Прочие параметры сохранены.

В результате хроматографического разделения на колонке $\mathrm{HP}-5 \mathrm{MS} 30 \mathrm{~m} \times 0,25 \mathrm{~mm} \times 0,25 \mu \mathrm{m}$ хлороформенных аквабитумоидов (ХБА) в относительно простой матрице (ХБА получены в ходе лабораторного эксперимента «нефть-вода») не удается достичь высокой степени селективности (рис. 1). Сложная природная матрица еще больше усложняет задачу разделения смеси, а наслоение масс-спектров коэлюирующихся компонентов затрудняет их идентификацию путем сравнения с библиотечными данными. 


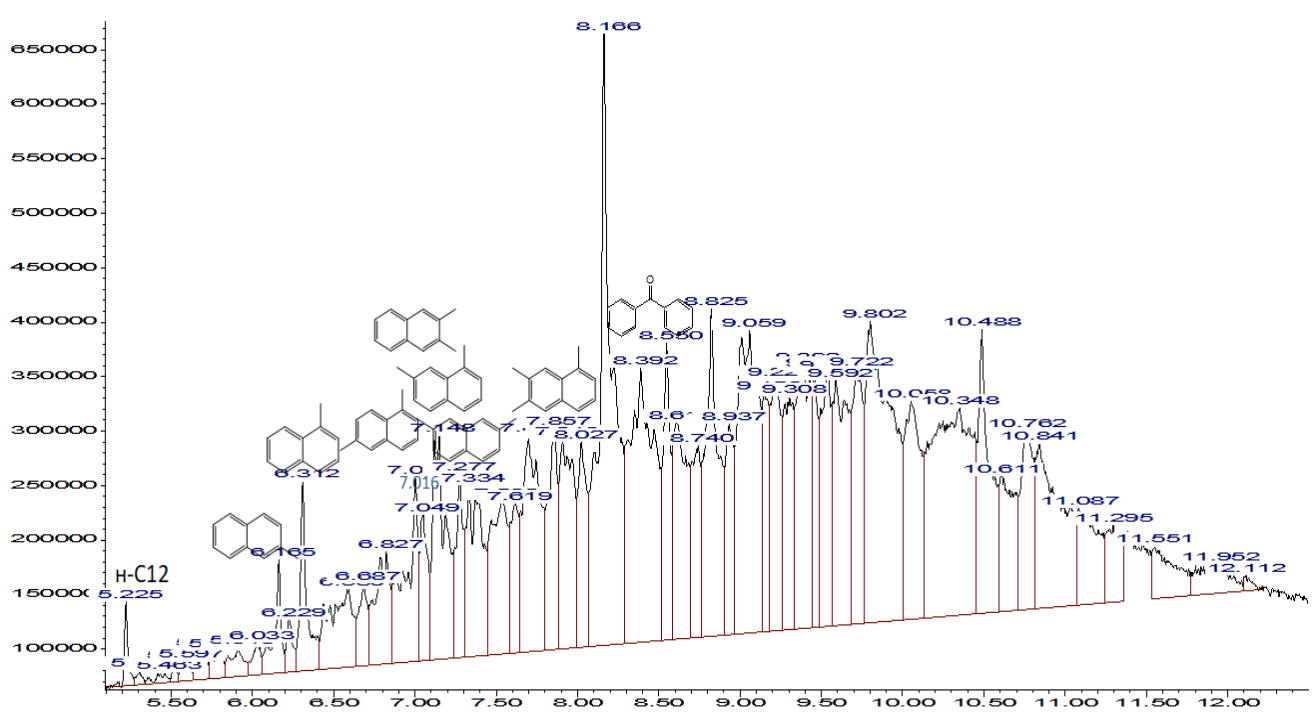

Рис. 1. Хроматограмма ХБА воды, 1 сутки контакта с нефтью, колонка HP-5MS $30 \mathrm{~m} \times 0,25 \mathrm{~mm} \times 0,25 \mu \mathrm{m}$

Использование дозатора равновесного пара вместо жидкостной экстракции позволяет существенно упростить матрицу и, следовательно, упростить профиль хроматограммы анализируемой смеси, что в свою очередь приводит к получению более «чистых» масс-спектров и повышает достоверность определения каждого компонента. Тем не менее, введение образца перепадом давления с последующей разгонкой на колонке HP-5MS $30 \mathrm{~m} \times 0,25 \mathrm{~mm} \times 0,25 \mu \mathrm{m}$ не приводит к удовлетворительному результату (рис. 2 ). Это связано, по-видимому, со слишком тонким слоем неподвижной фазы.

Основной проблемой масс-спектрометрической идентификации веществ, является невозможность достоверной идентификации изомерных структур. Это связано с тем, что характер масс-спектра изомеров практически одинаков, массы молекулярных и фрагментарных ионов не зависят от пространственного расположения атомов. Поэтому качественный анализ изомеров традиционно проводят по времени удерживания [9]. Таким образом, аналитическую задачу по разделению и качественному анализу водорастворенной органики удается решить при одновременном использовании метода газовой экстракции (статического парофазного анализа) и хроматографическом разделении на более длинной колонке с более толстым слоем 5\%-фенил-95\%-метилполисилоксана: DB-5MS $60 \times 0,25$ мм $\times 1$ мкм (рис. 3 ).

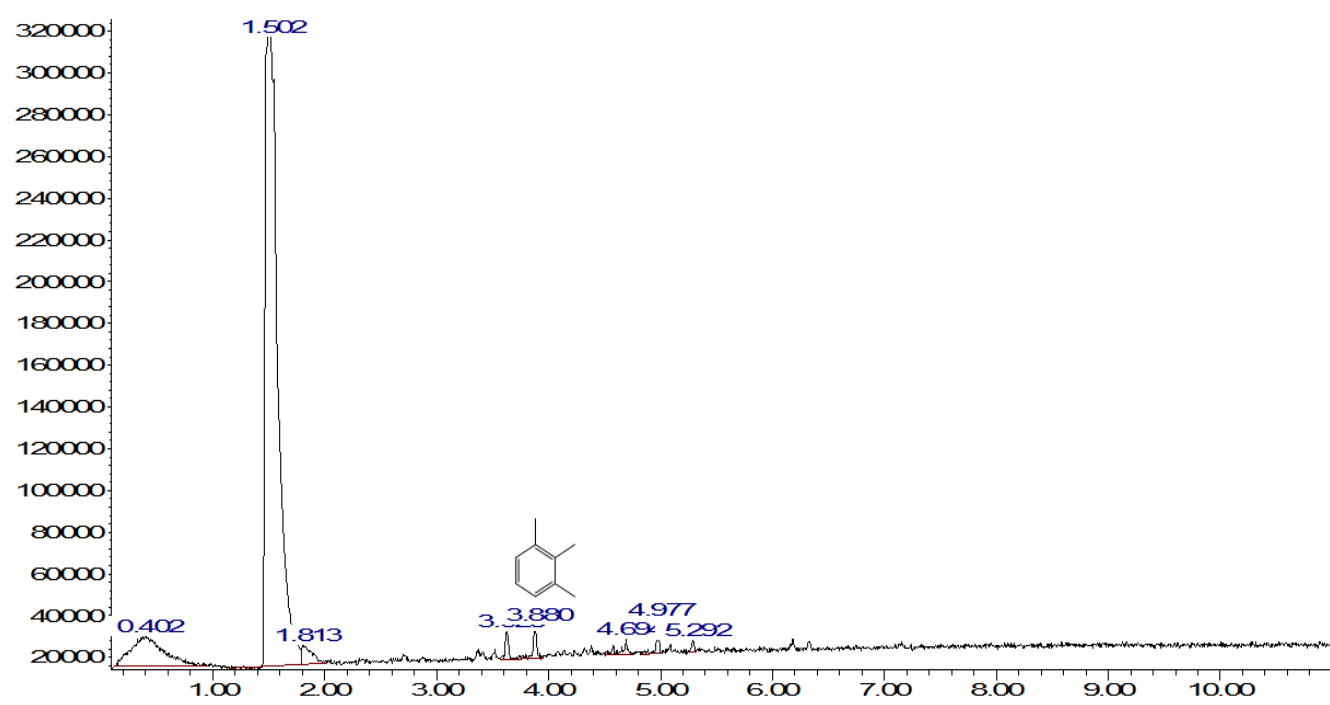

Рис. 2. Хроматограмма ЛОС воды, 1 сутки контакта с нефтью, колонка HP-5MS $30 \mathrm{~m} \times 0,25 \mathrm{~mm} \times 0,25 \mu \mathrm{m}$ 


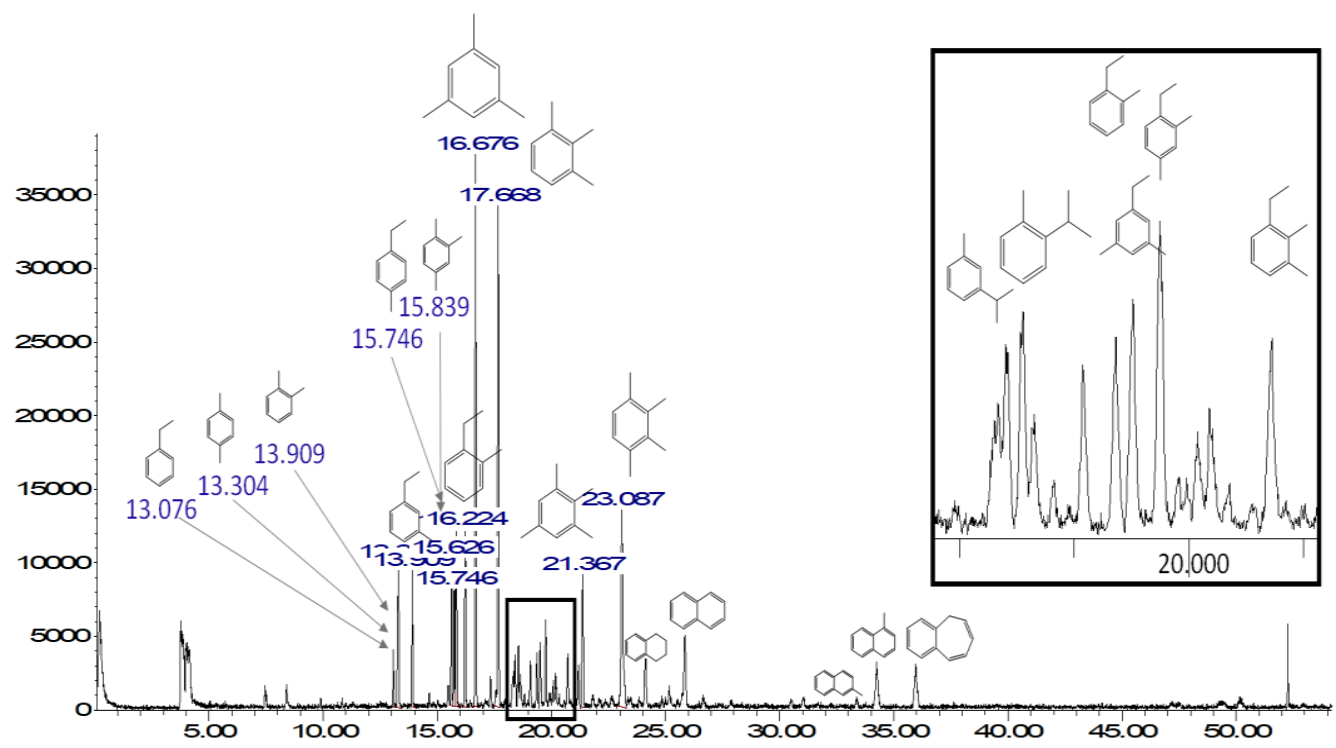

Рис. 3. Хроматограмма ЛОС воды, 1 сутки контакта с нефтью НЛ, Полазна, колонка DB-5MS $60 \times 0,25 \mathrm{Mм} \times 1$ мкм

Так удалось разделить и идентифицировать изомеры алкилированных бензолов: хроматографические и масс-спектральные характеристики наиболее разнообразных изомерных диметилэтилбензолов приведены в порядке элюирования в таблице 1, экспериментальные данные хорошо согласуются базами данных NIST и Wiley [10, 11].

Ранее установлено что, изменение условий хроматографирования по-разному влияет на различные гомологические ряды [12]. Сообщалось также и об успешном использовании в качестве реперных гомологических структур ароматических углеводородов: бензола, нафталина, фенантрена, хризена, пирена [13]. Поэтому расчет индекса удерживания по реперным ароматическим углеводородам $\left(\mathrm{I}_{\text {аром}}\right)$ представляется в данной ситуации наиболее корректным:

$$
I_{\text {аром }}=100 \cdot\left(\frac{\operatorname{lgt}_{R}(X)-\operatorname{lgt} t_{R}(n)}{\operatorname{lgt} t_{R}(n+1)-\operatorname{lgt} t_{R}(n)}\right)-100 \cdot n ;
$$

где $t_{R}(X)$ - время удерживания аналита, $t_{R}(n)$ и $t_{R}(n+1)$ - времена удерживания реперных ароматических углеводородов, $\mathrm{n}$ - число ароматических колец. При расчете индекса удерживания соблюдается условие $\mathrm{t}_{\mathrm{R}}(\mathrm{n})<\mathrm{t}_{\mathrm{R}}(\mathrm{X})<\mathrm{t}_{\mathrm{R}}(\mathrm{n}+1)$.

Таблица 1

Хромато-масс-спектрометрические характеристики изомерных диметилэтилбензолов

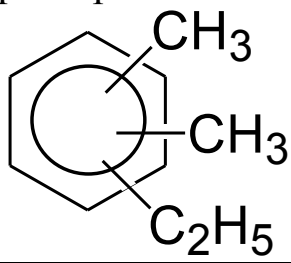

\begin{tabular}{|c|c|c|c|c|}
\hline & $\begin{array}{l}\text { Время удер- } \\
\text { живания }\end{array}$ & $\begin{array}{c}\text { Индекс по } \\
\text { ароматиче- } \\
\text { ским УВ }\end{array}$ & $\begin{array}{c}\text { Индекс Ко- } \\
\text { вача } \\
{[10,11]}\end{array}$ & Масс-спектр, m/z (I,\%) \\
\hline Бензол, 3,5-диметил-1 -этил- & 19.508 & 196.9 & 1065 & $\begin{array}{l}119(100) ; 134(34,7) ; 120(10,3) ; 91(8,7) ; 105 \\
(8,4) ; 77(6,3) ; 117(5,7) ; 65(4,9)\end{array}$ \\
\hline Бензол, 2,4-диметил-1-этил- & 19.744 & 198.3 & 1083 & $\begin{array}{l}119(100) ; 134(29,6) ; 91(11,0) ; 120(9,7) ; 77 \\
(5,8) ; 117(5,1) ; 105(4,7) ; 39(4,5)\end{array}$ \\
\hline Бензол, 1,4-диметил-2-этил- & 19.979 & 199.6 & 1085 & $\begin{array}{l}119(100) ; 134(33,2) ; 91(12,2) ; 105(11,8) ; 120 \\
(10,1) ; 77(6,2) ; 117(6,0) ; 115(4,3)\end{array}$ \\
\hline Бензол, 1,2-диметил-4-этил- & 20.081 & 200.1 & 1091 & $\begin{array}{l}119(100) ; 134(33,3) ; 91(12,4) ; 105(9,4) ; 120 \\
(9,0) ; 39(8,4) ; 77(8,2) ; 27(6,5)\end{array}$ \\
\hline Бензол, 1,3-диметил-2-этил- & 20.712 & 203.5 & 1097 & $\begin{array}{l}119(100) ; 134(29,0) ; 91(11,5) ; 120(8,9) ; 39 \\
(8,8) ; 77(8,1) ; 105(6,5) ; 27(5,9)\end{array}$ \\
\hline Бензол, 2,3-диметил-1-этил- & 20.722 & 203.6 & 1113 & $\begin{array}{l}119(100) ; 134(32,8) ; 91(13,3) ; 105(11,3) ; 39 \\
(9,4) ; 120(9,1) ; 77(9,0) ; 27(7,0)\end{array}$ \\
\hline
\end{tabular}


Хромато-масс-спектрометрический анализ алициклических углеводородов нефти традиционно является сложной аналитической задачей [12], однако шестидесятиметровая хроматографическая колонка со слоем 1 мкм 5\%-фенил-95\%-диметилполисилоксана в тандеме с парофазным дозатором позволяет успешно решать эту проблему.

Кроме успешного разделения диметилциклогексанов и диметилциклопентанов, удалось разделить изомерные диметилбензолы, изопропилметилбензолы, метилпропилбензолы, три- и тетраметилбензолы, метилнафталины.

Таким образом, применение ГX/MC с колонкой DB-5MS $60 \times 0,25$ мм $\times 1$ мкм в комплексе с парофазным дозатором TurboMatrix HS позволило получить надежные данные о молекулярном составе хлороформенного аквабитумоида представленного летучими органическими соединениями. Установлено, что при суточном контакте с нефтью без принудительного перемешивания в воду извлекаются в основном ароматические углеводороды, в меньшем количестве нафтеновые. Алифатические углеводороды не обнаружены.

\title{
БИБЛИОГРАФИЧЕСКИЙ СПИСОК
}

1. Мелькановицкая С.Г. Органические вещества подземных вод по данным газохроматографических исследований // Геохимия. - 1980. - № 2. - С. 272-284.

2. Витенберг А.Г. Статический парофазный газохроматографический анализ. Физико-химические основы и области применения // Российский химический журнал. - 2003. - T. XLVII. - № 1. - С. 7-22.

3. Другов Ю.С., Родин А.А. Пробоподготовка в экологическом анализе. - М.: БИНОМ. Лаборатория знаний, 2009. - 855 с.

4. Другов Ю.С., Родин А.А. Экологические анализы при разливах нефти и нефтепродуктов. -М.: БИНОМ. Лаборатория знаний, 2007. - 270 с.

5. Сотников Е.Е., Загайнов В.Ф., Михайлова Р.И., Милочкин Д.А., Рыжова И.Н., Корнилов И.О. Парофазный анализ летучих органических соединений в питьевой воде методом газовой хроматографии // Гигиена и санитария. - 2014. - № 2. - С. 92-96.

6. Крылов А.И., Лопушанская Е.М., Александрова А.Г., Конопелько Л.Л. Определение полиароматических углеводородов методом газовой хроматографии-масс-спектрометрии с изотопным разбавлением (ГХ/МС/ИР) // Аналитика. - 2012. - №3. - С.6-16.

7. Одинцова Т.А. Геохимическая характеристика состава аквабитумоидов нафтидного типа // Стратегия и процессы освоения георесурсов: сб. науч. тр. вып. 12 / ГИ УрО РАН. - Пермь, 2014. - С. 58-61.

8. Бачурин Б.А., Одинцова Т.А. Экоаналитическая идентификация источников органического загрязнения природных геосистем // Стратегия и процессы освоения георесурсов: сб. науч. тр. вып. 15 / ГИ УрО РАН. - Пермь, 2017. - С. 62-65.

9. Лебедев А.Т. Масс-спектрометрия в органической химии. - М.: БИНОМ. Лаборатория знаний, 2003. - 493 с.

10. Wang Z., Fingas M., Using Biomarker Compounds to Track the Source of Spilled Oil and to Monitor the Oil Weathering Process // LC GC-Magazine of separation science. - 1995. - V. 13, № 12. - P. 950-958.

11. Wang Z., Fingas M., Li K. Fractionation of a light crude oil and identification and quantitation of aliphatic, aromatic, and biomarker compounds by GC-FID and GC-MS. Part II // Journal of Chromatographic Science. - 1994. - V. 32, № 9. - P. 367-382. DOI: 10.1093/chromsci/32.9.367.

12. Петров А.А. Углеводороды нефти. - М.: Наука, 1984. - 263 с.: ил.

13. Павловский А.А. Проявление влияния динамической модификации неполярной фазы аналитами на их газохроматографические параметры удерживания: дис. ... канд. хим. наук; 02.00 .02 / Павловский Александр Алекспндрович. - СПб., 2016. - С. 16.

\section{МЕХАНИКА ГОРНЫХ ПОРОД}

УДК 622.831 .1

DOI:10.7242/echo.2019.3.7

\section{ОСОБЕННОСТИ ИСПОЛЬЗОВАНИЯ ЭФФЕКТА КАЙЗЕРА ДЛЯ ОЦЕНКИ НАПРЯЖЕННОГО СОСТОЯНИЯ МАССИВА ГОРНЫХ ПОРОД}

\author{
Н.Л. БЕЛЬТЮКОВ \\ Горный институт УрО РАН, г. Пермь
}

\begin{abstract}
Аннотация: В статье представлена перспективная концепция измерения напряжений в массиве пород на основе эффекта Кайзера. Рассмотрены основные теоретические модели, описывающие данное явление в породах, а также их следствия и фундаментальные ограничения. Выполнен обзор методов контроля напряжений, в которых используется эффект Кайзера, показаны их преимущества и недостатки.

Ключевые слова: акустическая эмиссия, эффект Кайзера, напряжения, массив горных пород, механизм трещинообразования.
\end{abstract}

